Supporting information

\title{
Synthesis of anionic metal-organic zeolites for selective gas adsorption and ions exchange
}

Yayong Sun, Fei Wang*, Jian Zhang*

State Key Laboratory of Structural Chemistry, Fujian Institute of Research on the Structure of Matter, Chinese Academy of Sciences, Fuzhou, Fujian 35002, China Fax: (+86)-591-83715030. E-mail address: wangfei04@,fjirsm.ac.cn; zhj@,fjirsm.ac.cn. 


\section{Materials and general procedures.}

All of the chemicals are commercial available, and used without further purification. MOZ-200 was collected on a SuperNova four-circle diffractometer at 293(2) K equipped with a mirror-monochromated $\mathrm{Cu}$ Ka radiation $(\lambda=1.54184 \AA)$ and MOZ201 was collected on a dtrek-CrysAlisPro-abstract goniometer at 293(2) K equipped with a graphite-monochromated Mo Ka radiation $(\lambda=0.71073 \AA)$. The structures of two MOZs were solved by direct methods and refined on $F_{2}$ by full-matrix, leastsquares methods using the SHELXL-97 program package. ${ }^{1-2}$ Elemental analyses of C and $\mathrm{H}$ were performed with an EA1110 CHNS-0 CE elemental analyzer. The IR (KBr pellet) spectra was recorded (400-4000 $\mathrm{cm}-1$ region) on a Nicolet Magna 750 FT-IR spectrometer. Thermogravimetric analyses (TGA) was carried out in an air atmosphere with a heating rate of $10^{\circ} \mathrm{C} / \mathrm{min}$ on a STA449C integration thermal analyzer. Powder X-ray diffraction (PXRD) datas were collected on a Rigaku MultiFlex diffractometer using $\mathrm{Cu} \mathrm{K} \alpha$ radiation. The $\mathrm{N}_{2}$ adsorption isotherms were recorded by using a micromeritics ASAP 2020 surface area and porosity analyzer. Fluorescence of the samples were performed using a FLS980 Spectrophotometer.

\section{Synthesis:}

Synthesis of $\left[\mathrm{N}\left(\mathrm{CH}_{3}\right)_{4}\right] \cdot\left[\mathrm{Zn}_{2}(\mathrm{bdc})(5-\mathrm{mtz})_{3}\right] \cdot 1.8 \mathrm{DMF} \quad(\mathbf{M O Z}-200)$ : The mixture of $\mathrm{Zn}\left(\mathrm{NO}_{3}\right)_{2} .6\left(\mathrm{H}_{2} \mathrm{O}\right) \quad(0.5 \mathrm{mmol}, \quad 0.148 \mathrm{~g}), \quad 5-\mathrm{Hmtz} \quad(0.5 \mathrm{mmol}, \quad 0.042 \mathrm{~g}), \quad 1,4-$ dicarboxybenzene $(0.5 \mathrm{mmol}, 0.0830 \mathrm{~g})$, two drops of etramethylammonium hydroxide $(25 \mathrm{wt} \%)$ and $5 \mathrm{ml}$ DMF were sealed in a $20 \mathrm{ml}$ vial. The mixture was heated at $120{ }^{\circ} \mathrm{C}$ for $24 \mathrm{~h}$ and then cooled to room temperature. Colorless prism crystals of the product were formed and collected by ltration and then washed with DMF several times (yield: $83 \%$ based on 5-mtz). Anal. Calcd for $\mathrm{C}_{11.7} \mathrm{H}_{18.8} \mathrm{~N}_{7.4} \mathrm{O}_{2.9} \mathrm{Zn}$ (374.6): C, 28.8; H, 4.23; N, 17.08. Found: C, 37.5; H, 5.0; N, 27.6. IR (cm-1): 2930 w, 2356 w, 1661 m, 1589 s, 1510 m, 1390 s, 1151 w, 1095 w, 1006 w, 823 m, 751 s, 655 w, 825 s, 727 s, 709 s, $669 \mathrm{~s}$.

Synthesis of $\left[\mathrm{N}\left(\mathrm{CH}_{3}\right)_{4}\right] \cdot\left[\mathrm{Zn}_{2}(\mathrm{idc})(5-\mathrm{mtz})_{3}\right] \cdot 1.8 \mathrm{DMF} \quad($ MOZ-201): The mixture of $\mathrm{Zn}\left(\mathrm{NO}_{3}\right)_{2} .6\left(\mathrm{H}_{2} \mathrm{O}\right) \quad(0.5 \mathrm{mmol}, \quad 0.148 \mathrm{~g}), \quad 5-\mathrm{Hmtz} \quad(0.5 \mathrm{mmol}, \quad 0.042 \mathrm{~g}), \quad 5-$ Hydroxyisophthalic acid $(0.5 \mathrm{mmol}, 0.0830 \mathrm{~g})$, two drops of etramethylammonium 
hydroxide $(25 \mathrm{wt} \%)$ and $5 \mathrm{ml} \mathrm{DMF}$ were sealed in a $20 \mathrm{ml}$ vial. The mixture was heated at $120{ }^{\circ} \mathrm{C}$ for $24 \mathrm{~h}$ and then cooled to room temperature. Colorless prism crystals of the product were formed and collected by ltration and then washed with DMF several times (yield: $78 \%$ based on 5-mtz). Anal. Calcd for $\mathrm{C}_{11.7} \mathrm{H}_{18.8} \mathrm{~N}_{7.4} \mathrm{O}_{3.4} \mathrm{Zn}$ (384.3): C, 32.82; H, 4.56; N, 25.26. Found: C, 36.5; H, 4.9; N, 26.9. IR (cm-1): 3727 w, 2945 w, 2364 w, 1493 m, 1358 s, 1278 m, 1215 w, 1103 w, 943 w, 879 w, $775 \mathrm{~s}, 736 \mathrm{~m}, 688 \mathrm{~m}$.

\section{$\mathrm{Ln}^{3+}$ ions exchange of MOZ-200.}

To the DMF solution $(6 \mathrm{~mL})$ of $\mathrm{Ln}\left(\mathrm{NO}_{3}\right)_{3}(0.60 \mathrm{~g}), 0.06 \mathrm{~g}$ of MOZ-200 was added.

Then the mixture was standing for $48 \mathrm{~h}$. Before the fluorescence study, the exchanged samples were filtered off, washed with ethanol for several times until no characteristic emission was observed upon excitation, and then dried in air.

Table S1. Crystal Data and Structure Refinements for MOZ-200 and MOZ-201

\begin{tabular}{|c|c|c|}
\hline & MOZ-200 & MOZ-201 \\
\hline Empirical formula & $\mathrm{C}_{18} \mathrm{H}_{25} \mathrm{~N}_{13} \mathrm{O}_{4} \mathrm{Zn}_{2}$ & $\mathrm{C}_{18} \mathrm{H}_{25} \mathrm{~N}_{13} \mathrm{O}_{5} \mathrm{Zn}_{2}$ \\
\hline Formula weight & 618.25 & 634.25 \\
\hline Temperature/K & $295.1(9)$ & $293(2)$ \\
\hline Crystal system & tetragonal & tetragonal \\
\hline Space group & $\mathrm{P}_{2} / \mathrm{ncm}$ & $P 4_{2} / n m c$ \\
\hline$a / \AA$ & $30.7475(6)$ & $31.199(8)$ \\
\hline$b / \AA$ & $30.7475(6)$ & $31.199(8)$ \\
\hline$c / \AA$ & $9.9133(3)$ & $10.196(4)$ \\
\hline$\alpha /^{\circ}$ & 90 & 90 \\
\hline$\beta /^{\circ}$ & 90 & 90 \\
\hline$\gamma /{ }^{\circ}$ & 90 & 90 \\
\hline$V / \AA ̊ 3$ & $9372.1(5)$ & $9924(6)$ \\
\hline$Z$ & 8 & 8 \\
\hline pcalcg/cm3 & 0.876 & 0.849 \\
\hline$\mu / \mathrm{mm}-1$ & 1.509 & 0.996 \\
\hline$F(000)$ & 2528.0 & 2592.0 \\
\hline Rint & 0.1017 & 0.0781 \\
\hline $\mathrm{N}_{\text {ref }}, \mathrm{N}_{\mathrm{par}}$ & 24862,4412 & 62737,5888 \\
\hline Data/restraints/parameters & $4412 / 0 / 180$ & $5888 / 0 / 172$ \\
\hline$S$ & 1.149 & 1.091 \\
\hline$R_{1}, w R_{2}[\mathrm{I}>=2 \sigma(\mathrm{I})]^{a}$ & $R_{1}=0.1087, w R_{2}=0.3201$ & $R_{1}=0.1019, w R_{2}=0.3013$ \\
\hline$R_{1}, w R_{2}$ [all data] ${ }^{b}$ & $R_{1}=0.1466, w R_{2}=0.3381$ & $R_{1}=0.1420, w R_{2}=0.3424$ \\
\hline
\end{tabular}




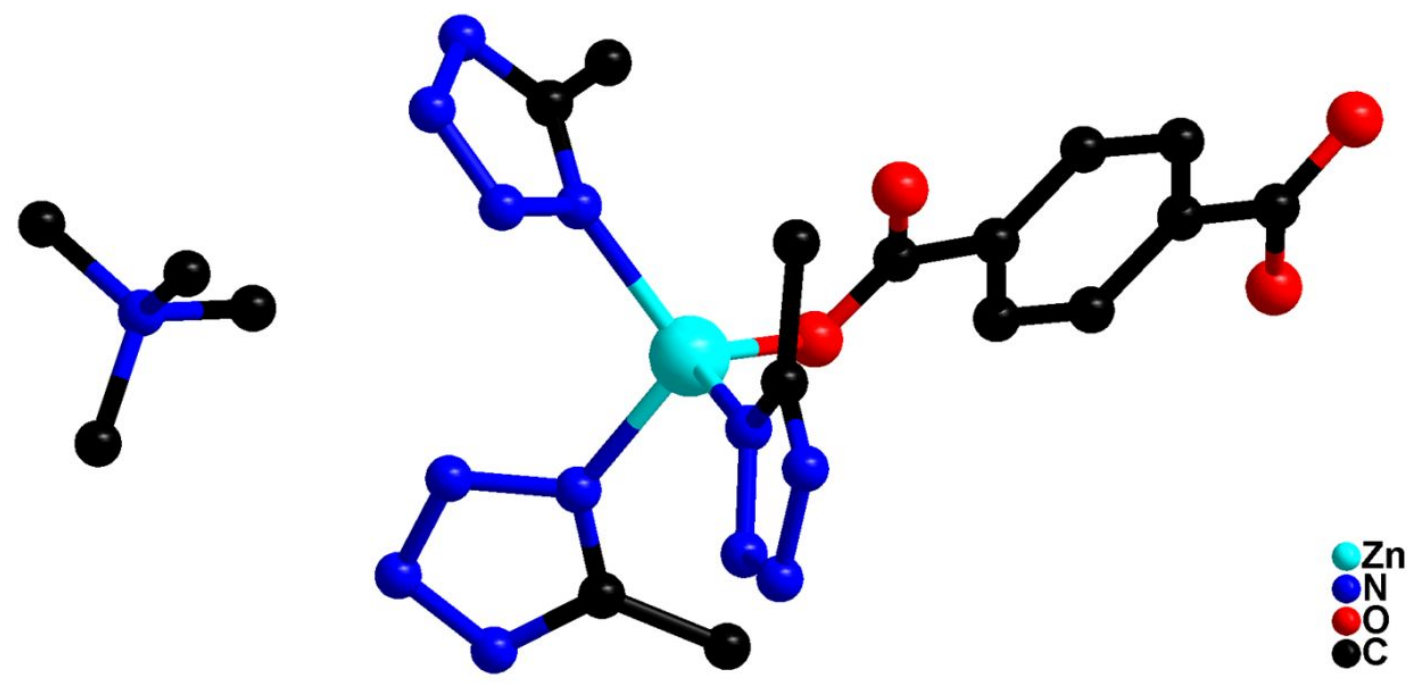

Figure S1 The coordination environment of MOZ-200

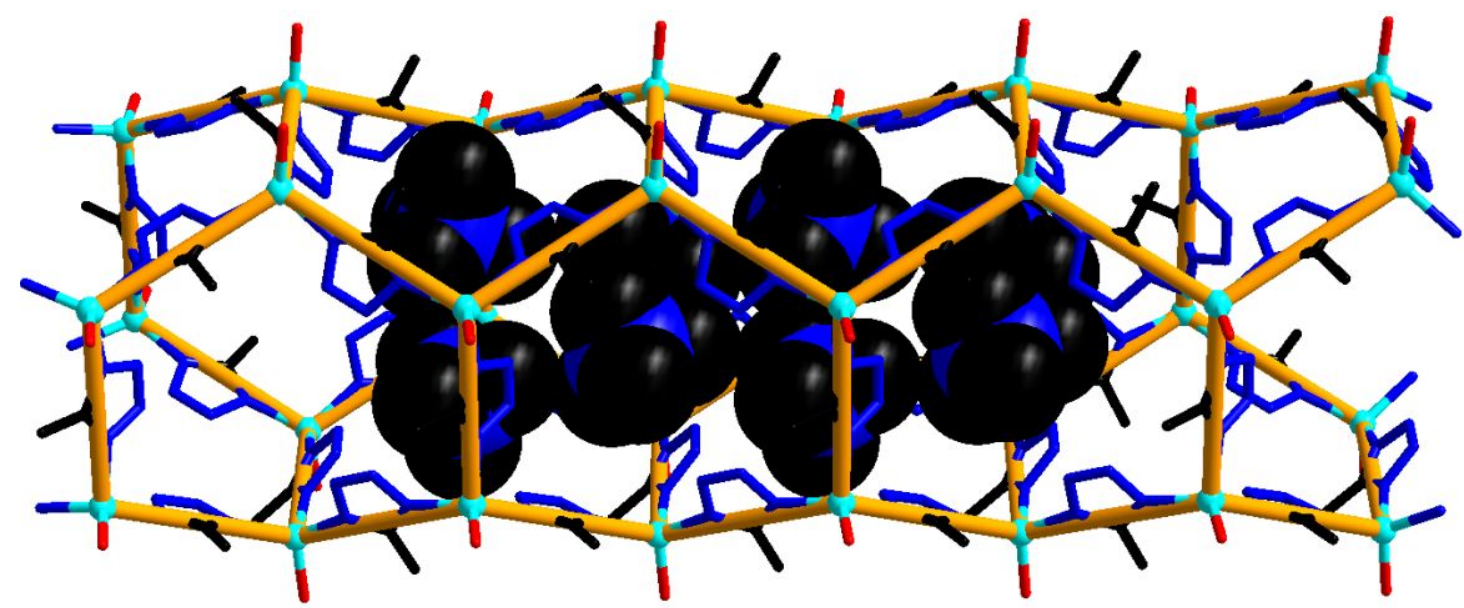

Figure S2. The 1D Zn-tetrazolate octolateral channels were filled by $\left[\mathrm{N}\left(\mathrm{CH}_{3}\right)_{4}\right]^{+}$cations. 


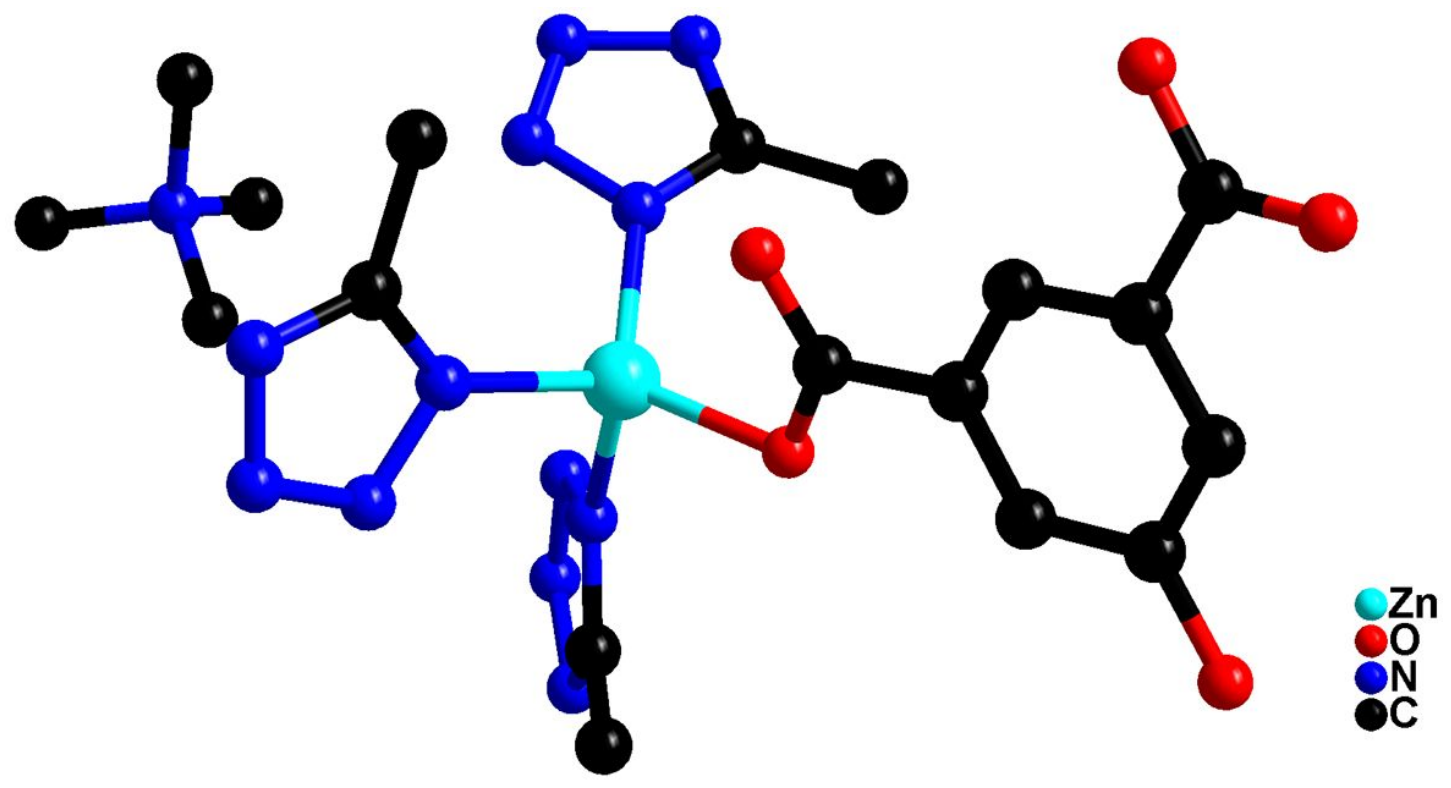

Figure S3 The coordination environment of MOZ-201
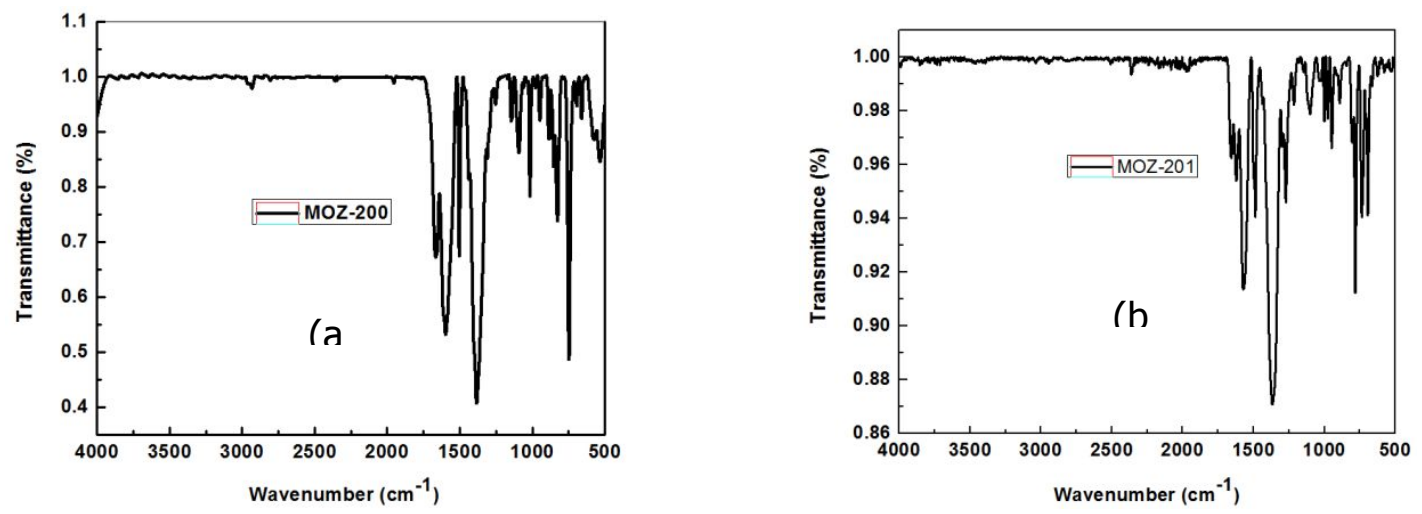

Figure S4. The IR curves for MOZ-200 (a) and MOZ-201(b). 

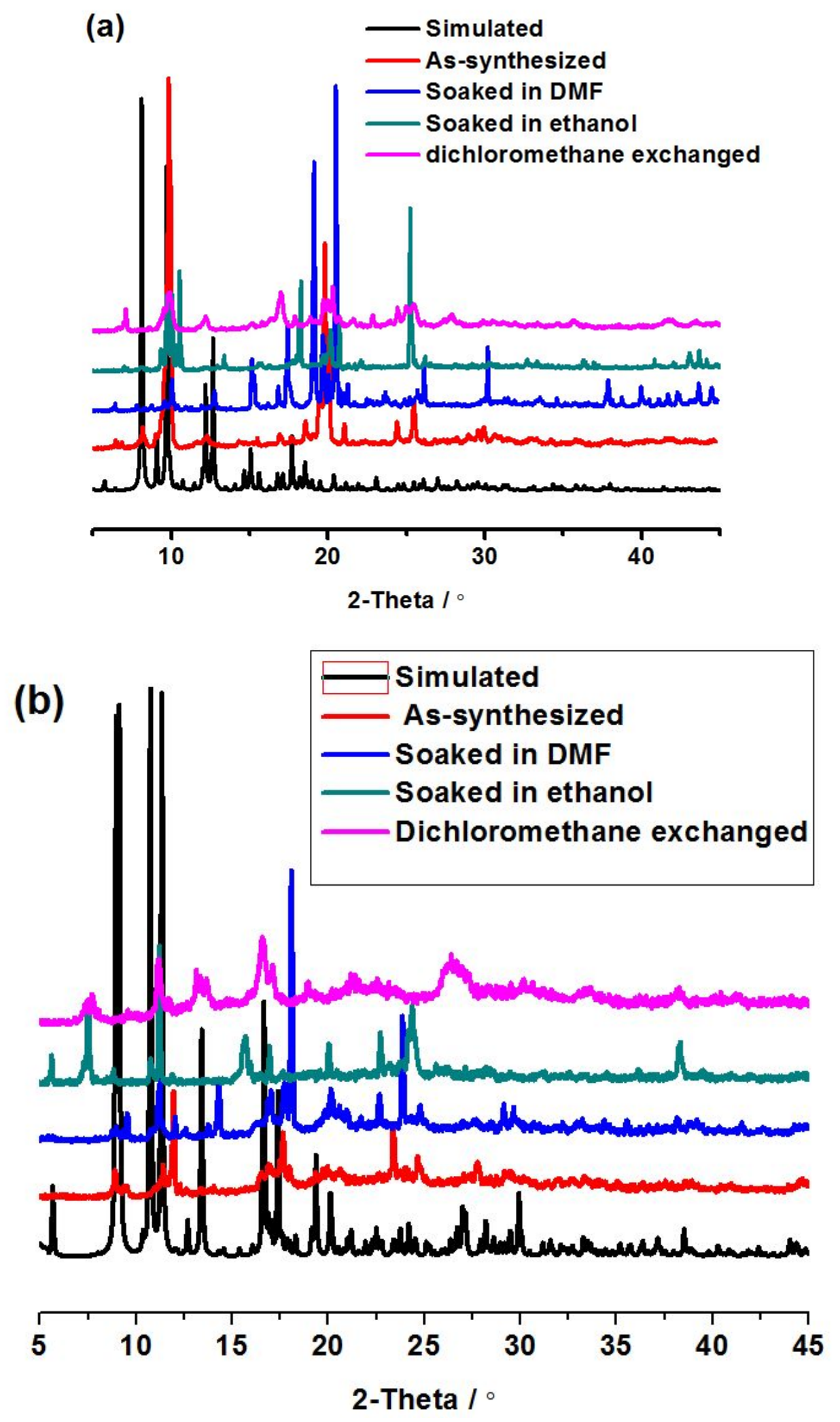

Figure S5. The Powder XRD patterns of MOZ-200 (a) and MOZ-201 (b) after soaking in different solvents. 


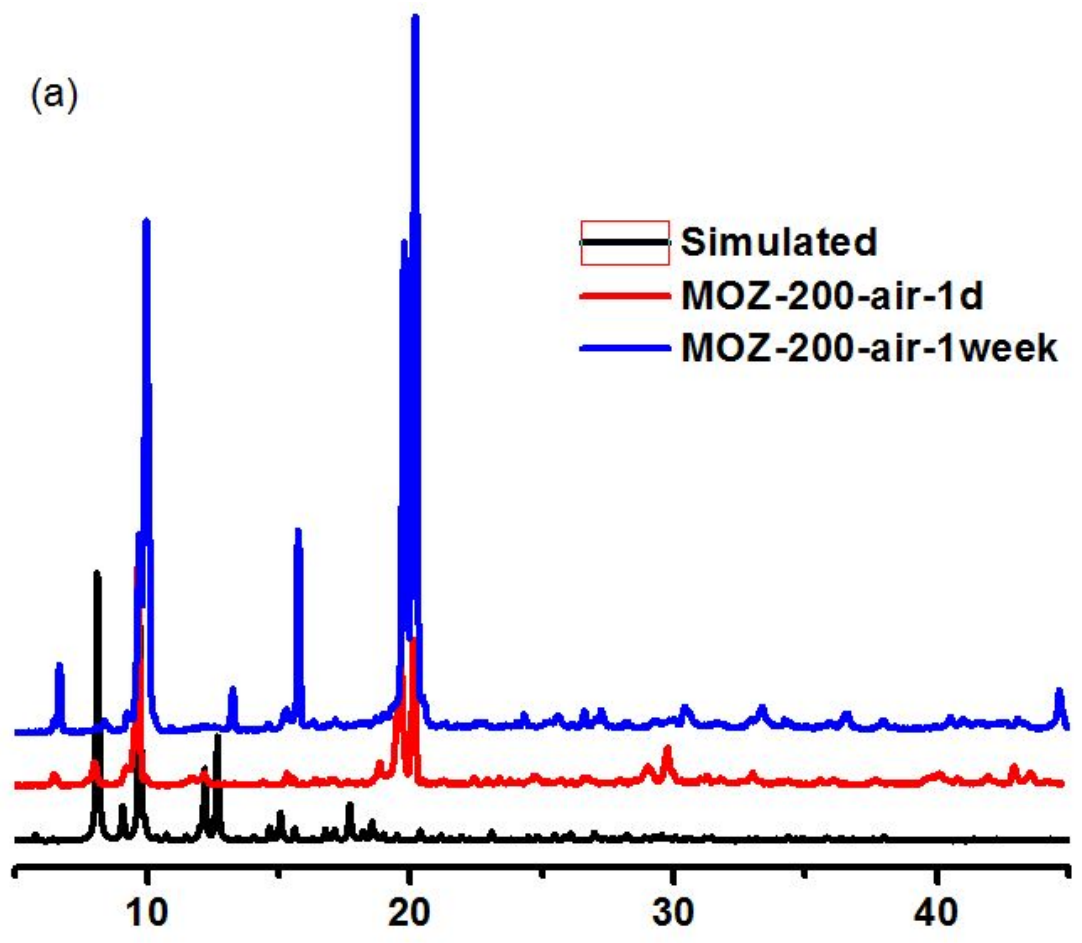

2-Theta $I^{\circ}$

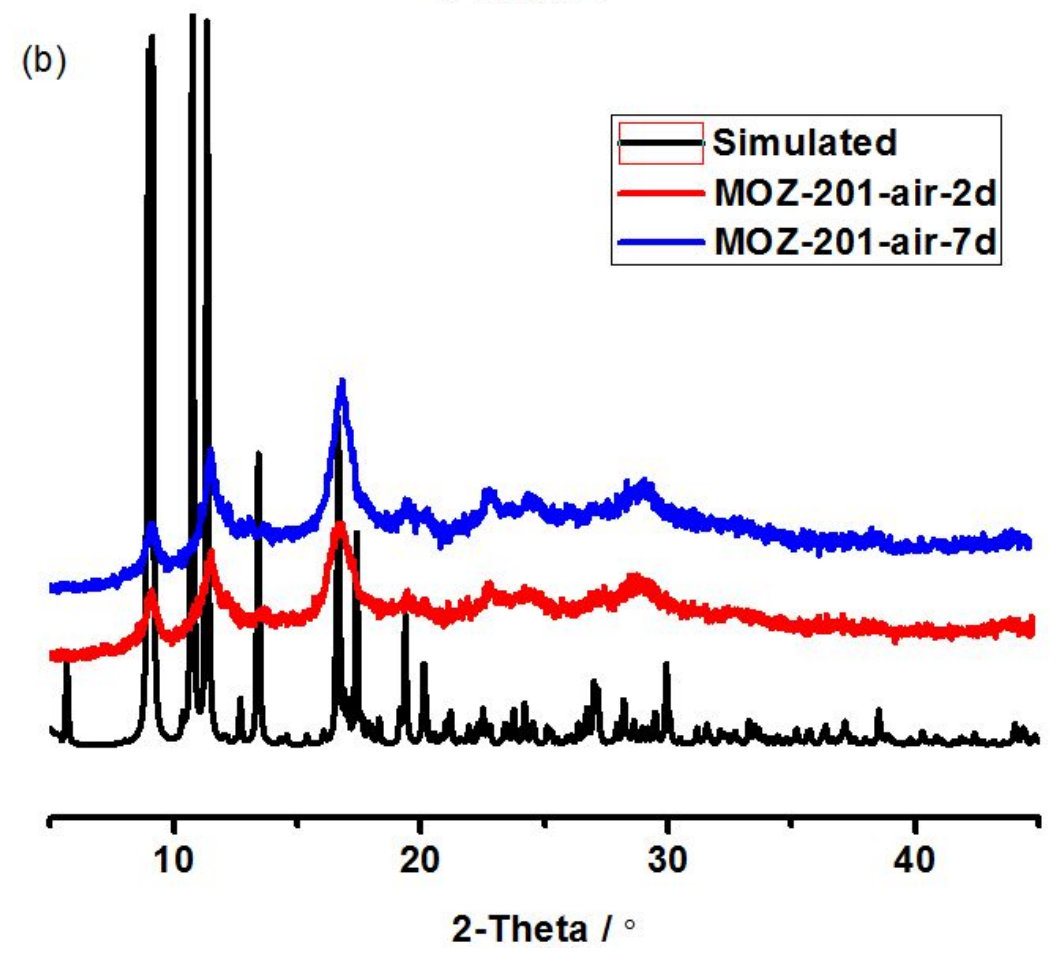

Figure S6. The PXRD patterns of MOZ-200 (a) and MOZ-201 (b) in air. 

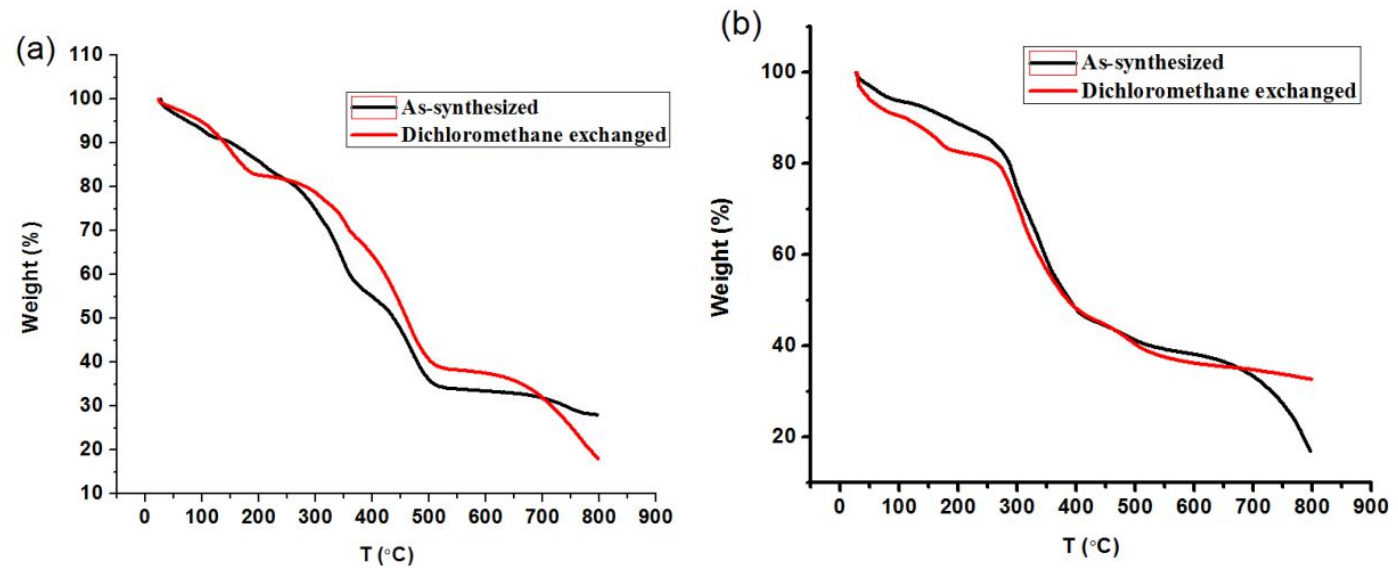

Figure S7. The TG plots of MOZ-200 (a) and MOZ-201 (b).

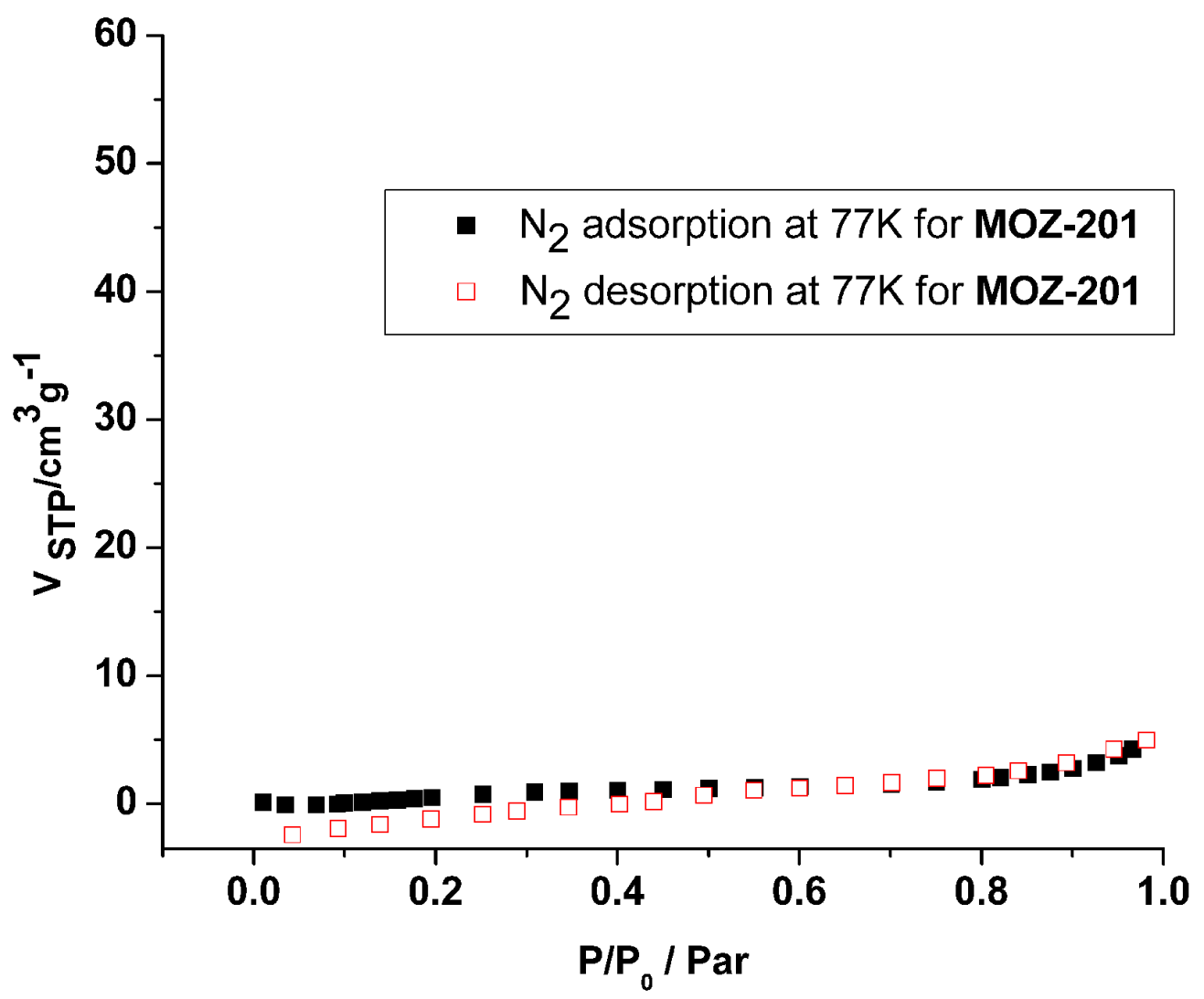

Figure S8. $\mathrm{N}_{2}$ adsorption isotherms at $77 \mathrm{~K}$ for MOZ-201. 


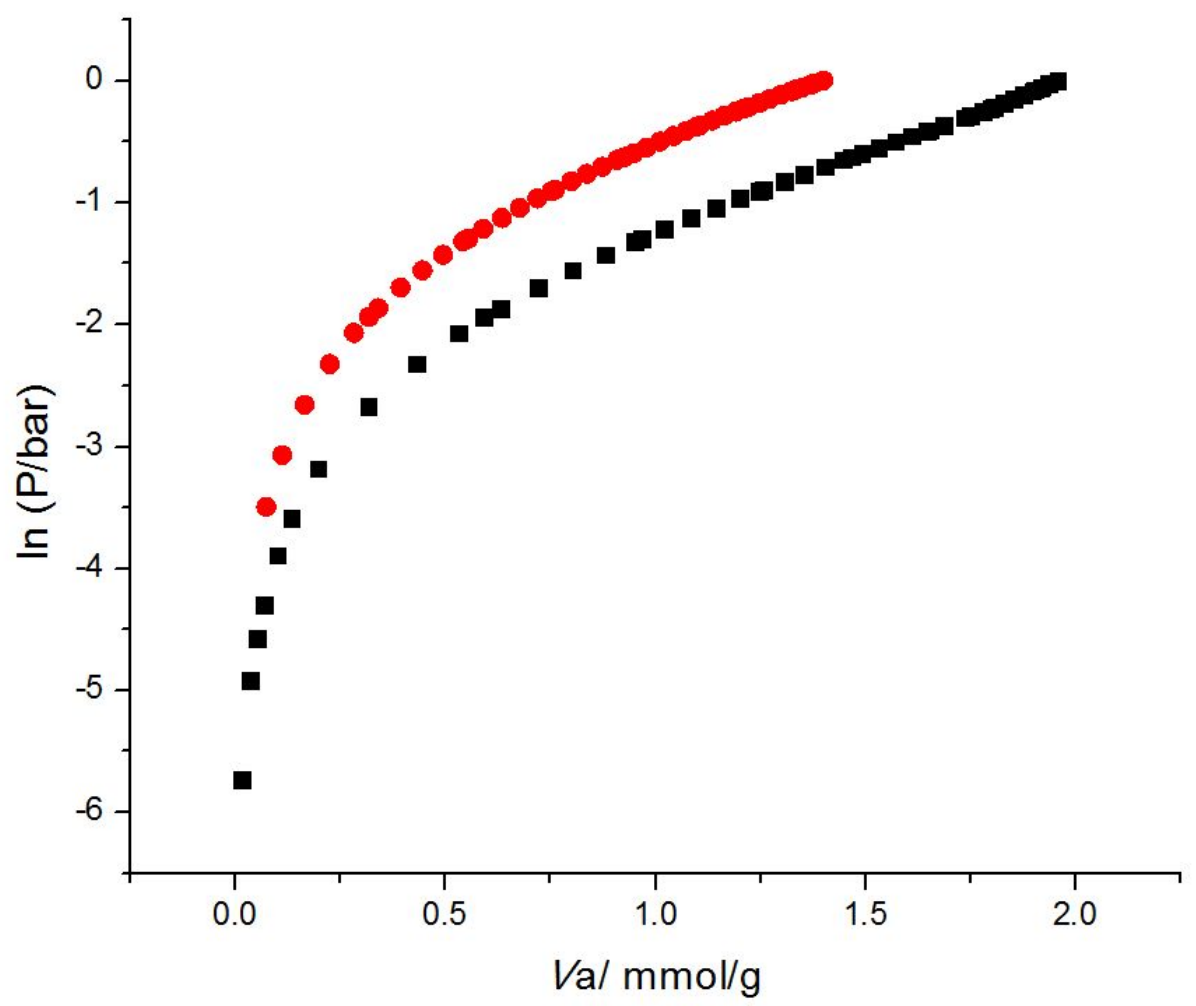

Figure S9. The $\mathrm{CO}_{2}$ sorption isotherms for MOZ-200 fitting by virial method.

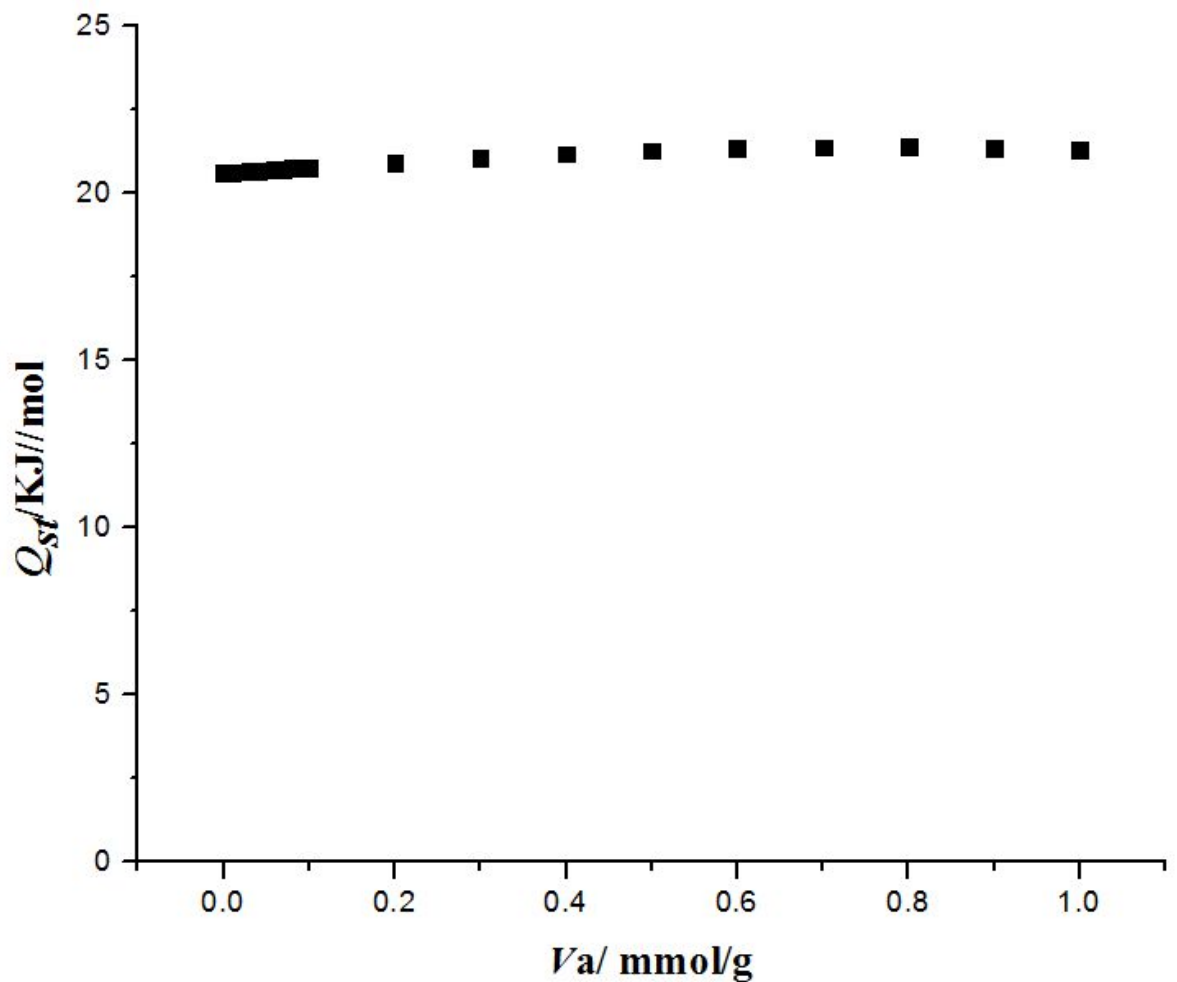

Figure $\mathrm{S} 10$. The isosteric heat of $\mathrm{CO}_{2}$ adsorption for MOZ-200 estimated by the virial equation. 


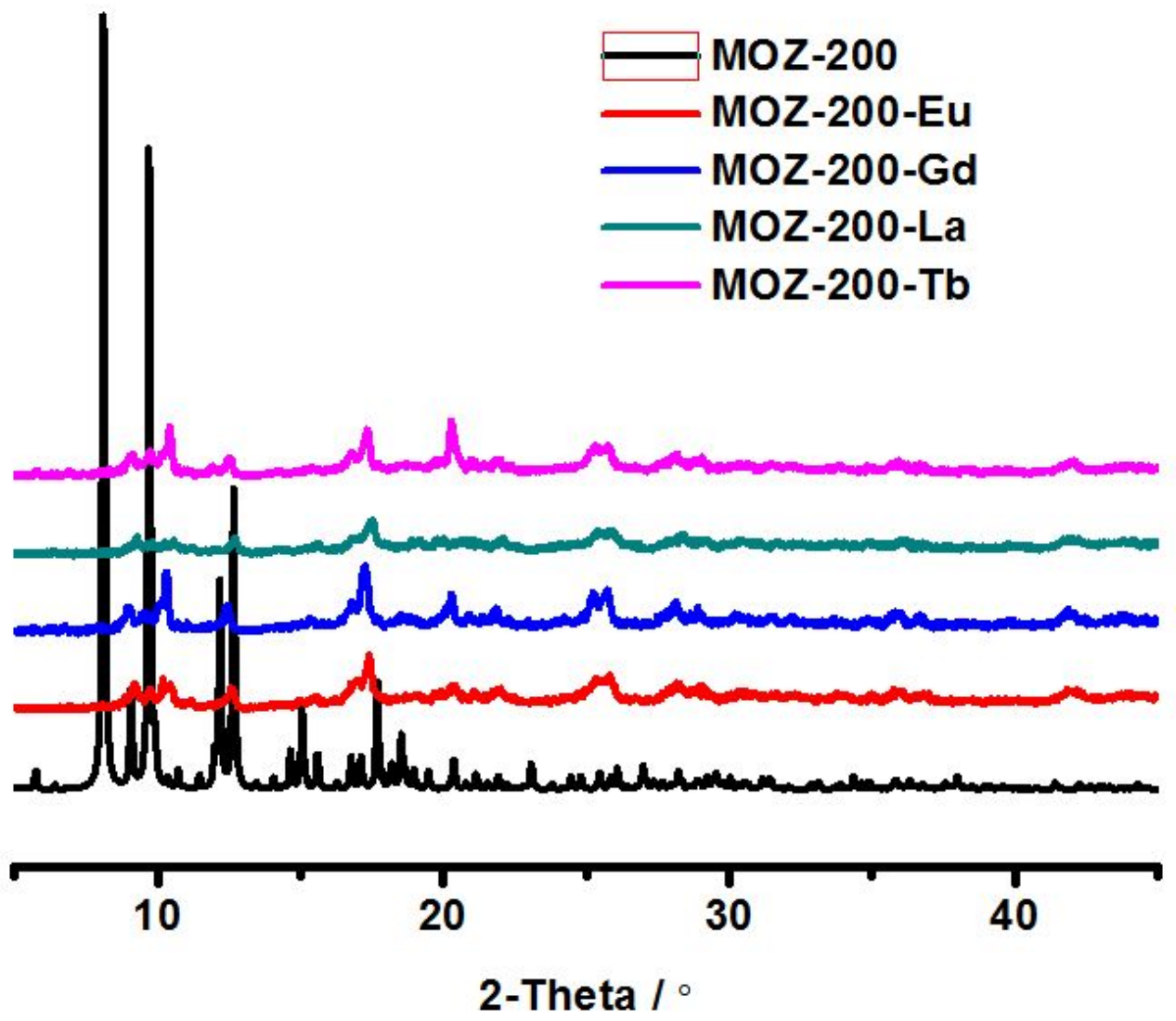

Figure S11. The PXRD patterns of $\mathrm{Ln}^{3+} @ \mathbf{M O Z - 2 0 0}\left(\mathrm{Ln}^{3+}=\mathrm{La}^{3+}, \mathrm{Eu}^{3+}, \mathrm{Tb}^{3+}\right.$ and $\left.\mathrm{Gd}^{3+}\right)$, respectively.

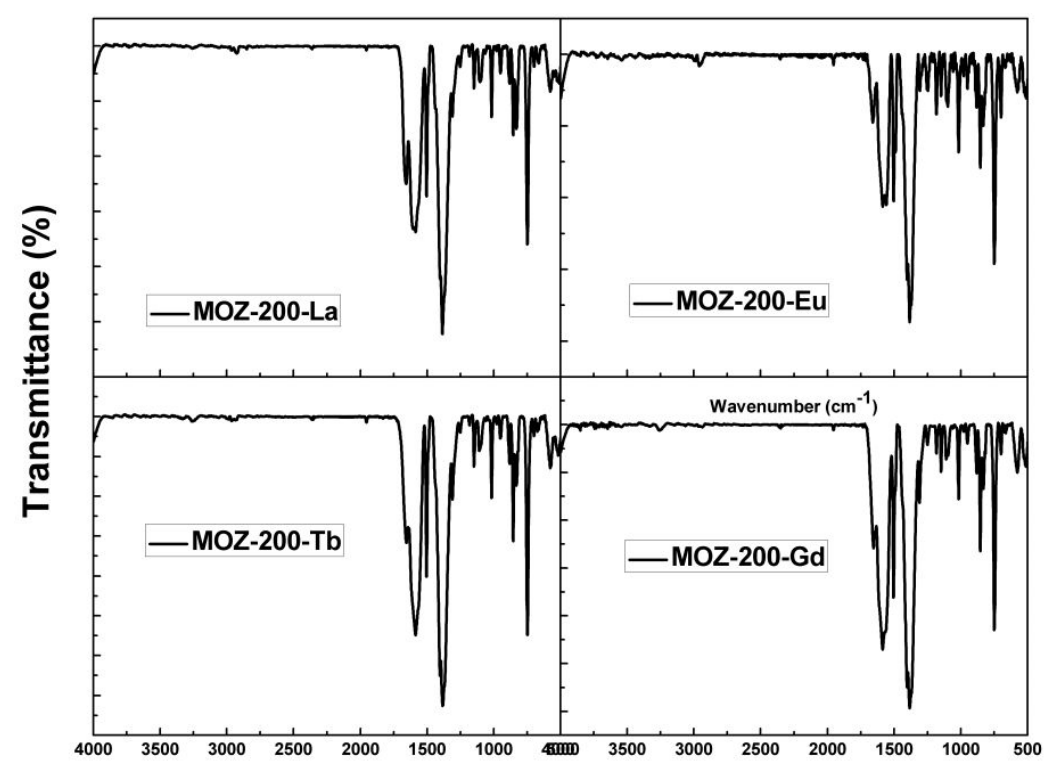

Wavenumber $\left(\mathrm{cm}^{-1}\right)$

Figure S12. The IR curves for $\mathrm{Ln}^{3+} @ \mathbf{M O Z - 2 0 0}\left(\mathrm{Ln}^{3+}=\mathrm{La}^{3+}, \mathrm{Eu}^{3+}, \mathrm{Tb}^{3+}\right.$ and $\left.\mathrm{Gd}^{3+}\right)$, respectively. 


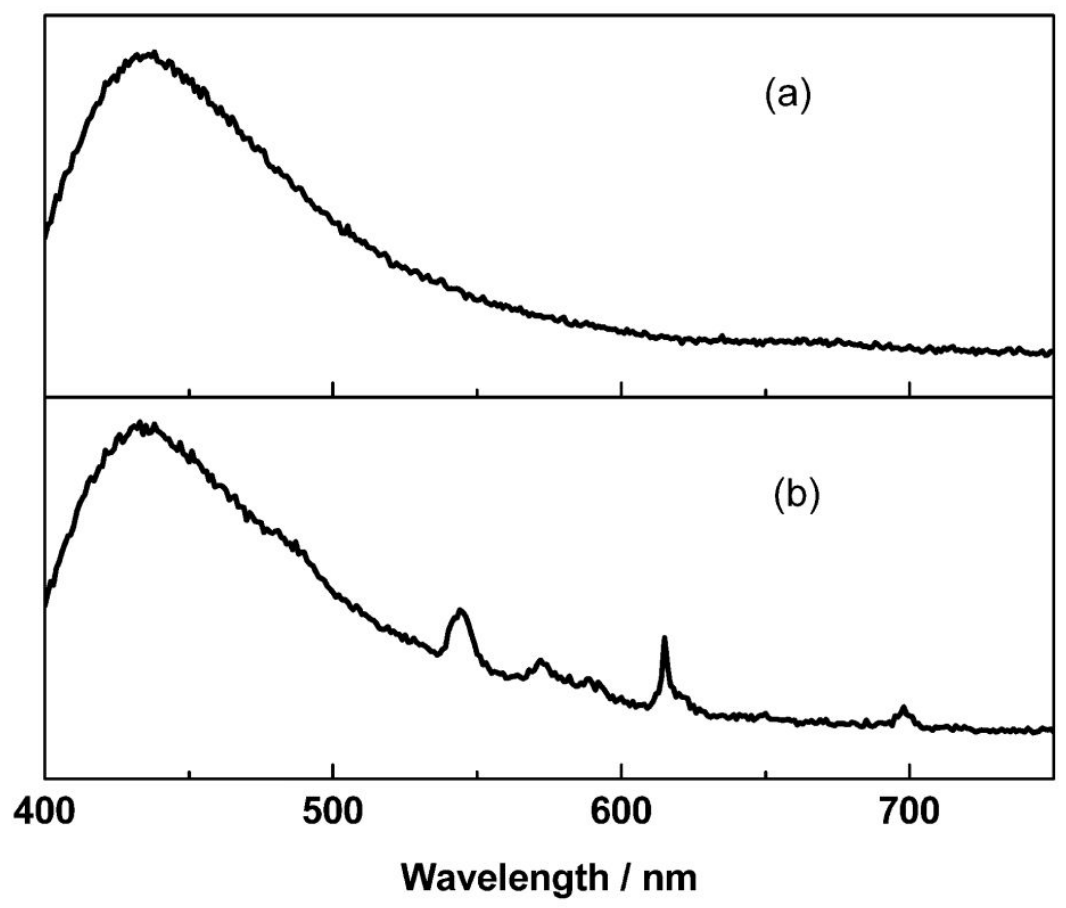

Figure S13. the luminescence spectra of La ${ }^{3+} @$ MOZ-200 (a) and Gd ${ }^{3+} @$ MOZ-200 (b) under $365 \mathrm{~nm}$ excitation wavelength.

(1) Sheldrick, G. M. Acta Crystallogr. 2008, A64, 112-122.

(2) Sheldrick, G. M. SHELXL-97, Program for Crystal Structure Solution and Refinement; University of Göttingen: Göttingen, Germany, 1997. 